\title{
Correction to: Energy and exergy efficiency analysis of solar still incorporated with copper plate and phosphate pellets as energy storage material
}

\author{
Rajendra Prasad Arani ${ }^{1} \cdot$ Mohammed El Hadi Attia $^{2}$ - Wael Al-Kouz ${ }^{3}$. Asif Afzal ${ }^{4} \cdot$ Muthu Manokar Athikesavan $^{5}$ (D) \\ Ravishankar Sathyamurthy ${ }^{6}$
}

Published online: 13 May 2021

(C) Springer-Verlag GmbH Germany, part of Springer Nature 2021

\section{Correction to: Environmental Science and Pollution Research} https://doi.org/10.1007/s11356-021-14080-5

The correct Country of affiliation 1 is India.

The original article has been corrected.

Publisher's note Springer Nature remains neutral with regard to jurisdictional claims in published maps and institutional affiliations.

The online version of the original article can be found at https://doi.org/ 10.1007/s11356-021-14080-5

Muthu Manokar Athikesavan

a.muthumanokar@gmail.com

1 Department of Mechanical Engineering, Sri Sairam Engineering College, Chennai, Tamil Nadu 600044, India

2 Department of Physics, Faculty of Sciences, University of El Oued, 39000 El Oued, Algeria

3 Mechanical and Maintenance Engineering Department, German Jordanian University, Amman 11180, Jordan

4 Department of Mechanical Engineering, P. A. College of Engineering (Affiliated to Visvesvaraya Technological University Belagavi), Mangaluru 574153, India

5 Department of Mechanical Engineering, B.S. Abdur Rahman Crescent Institute of Science and Technology, Chennai, Tamil Nadu 600 048, India

6 Department of Mechanical Engineering, KPR Institute of Engineering and Technology, Arasur, Coimbatore, Tamil Nadu, India 